\title{
KAJIAN PENERIMAAN PEMBELAJARAN MEMBACA ANAK USIA DINI BERDASARKAN KONSEP TECHNOLOGY ACCEPTANCE MODEL
}

\author{
Yuthsi Aprilinda" \\ Program Studi Teknik Informatika \\ Fakultas Ilmu Komputer \\ Universitas Bandar Lampung
}

Jn. Z A. Pagar Alam No.26 Labuhan Ratu Bandar Lampung 35142

Telp. (0721) 701463, (0721) 701979 Fax. (0721) 701467 Web. www ubl as id

E-mail: yuthsi apriläyuhoo com "yuthsi.aprilinda(a ubl ac. id ")

Handphone: $081927886363^{11}$

\begin{abstract}
Abstrak
Penelitian int membahas mengenai penerimaan Software Education Cara Membaca yang dapat dideteksi dari persepsi dan perilaku penggruna dalam penggunaannya di Sekolah Pendidikan Usia Dini (PAUD) seperi Taman Kanak-Kanak, Play Group (Kelompok Bermain). Penelitian imi bertujuan sunuk mengetahu faktor-faktor yang mempengaruhi diterima dengan baik atau tidaknya Software Education Cara Membaca oleh anak usia dini. Juga ingin diketahui Iubungan aniara faktor-faktor yang mempengaruhi penerimaan Sofhware Education tersebut. Model yang digunakan unisk mengetahui penerimaan Raharja Multimedia Edutainment in adaiah model TAM (Technology Acceptance Model). Secara terinci model TAM menjelaskan penerimaan Tl dengan dimensi-dimensi ueriensu yang dapat mempengaruhi penerimaan teknologi oleh pengguna. Madel ini menempaikan faksor sikap dan tiap-iiap perilaku pengguna dengan menggunakam dua variabel uama yainu kemanfaatan (usefulness) dan kemudahan penggumaan (easy of use). Diduga penerimaan Software Education Cara Membaca ini juga dipenganuhi oleh fakor lain aniara lain : Atutude Toward Using (ATU) aiau sikap untuk menggunakan, intention to Use (ITU) atat mat untuk menggunakan terhadap produk/servis dan Actual System Usage (ASU) atau perilaku penggunaan.
\end{abstract}

Kata kunci : TAM, usefulness, easy of use, PAUD

\section{PENDAHULUAN}

Pada era globalisasi seperti sekarang ini teknologi informasi memegang peranan yang sangat penting pada berbagai aspek kehidupan. Hal ini dapat dipahami karena keberadaan teknologi informasi tersebut dapat memenuhi kebutuhan informasi dengan cepat, tepat, relevan dan akurat sehingga dapat digunakan oleh pengguna teknologi dalam membantu menyelesaikan pekerjaan. Untuk memenuhi kebutuhan informasi yang relevan, cepat, dan akurat tersebut, maka penerapan teknologi informasi khususnya yang berbasis komputer tidak dapat terlepas dari peranan tiga komponen dasar komputer yaitu berupa (1) pernangkat keras (hardware) (2) Perangkat lunak (sofhvare) dan (3) pengguna (braimvare).
Suksesnya penerapan teknologi informasi sangat bergantung pada penerimaan olch user sebagai pengguna teknologi. (Davis, 1989 : p79) telah mengembangkan suatu model penerimaan teknologi (TAM = Technology Acceptance Model) untuk menjelaskan dan memprediksi peneriman teknologi oleh user. Model TAM secara terinci menjelaskan penerimaan teknologi informasi dengan dimensi-dimensi tertentu yang dapat mempenganuhi penerimaan teknologi oleh pengguna Model ini menempatkan faktor sikap, niat, dan perilaku pengiuna dengan menggunakan 2 variabel masukan utama yaitu kemanfaatan (usefulness) dan kemudahan (casy of use). Secara empiris model ini telah terbukti memberikan gambaran perilaku pengguna teknologi informasi, yakni banyak peagguna teknologi informasi dapat menerima TI karena sesuai dengan apa yang diinginkan 
Iqbaria, 1997:p86), Hasil inovasi para spesialis di bidang teknologi informasi dalam mengembangkan perangkat lunak baru secara berkelanjutan dan dalam skala besar, telah mempersingkat umur teknis dan umur ekonomis dari perangkat lunak sebelumnya.

Studi kasus kali ini membahas pengganaan teknologi pembelajaran can membaca anak usia dini berupa Software Education untuk pembelajaran cara membaca anak usia dini , di beberapa sekolah PAUD (Pendidikan Anak Usia Dini) di Bandar Lampung. Belajar membaca untuk anak-anak terkadang sangat susah dilakukan. Perlu berbagai trik yang harus dilakukan agar si anak terangsang untuk mau belajar membaca. yang perlu diperhatikan adalah bahwa setiap anak mempunyai karakteristik sendiri-sendiri. Satu metoda bisa efektif bagi seorang anak akan tetapi mungkin tidak bisa diterapkan pada anak lain. Kejelian kita sebagai orang tun yang harus bisa membaca sifat si anak dan memberikan metoda yang paling cocok bagi si anak untuk mula belajar membeca.

Belajar membaca sebisa mungkin menjadikan suatu keasikan pada si anak, jangan sampai justru anak merasa tertekan dengan proses belajar membacit. Disinilah letak kejelian kita melihat kondisi anak, bagaimana kita memasukkan proses belajar membaca pada dunia bermain mereka, Kegemaran anak relutif adalah menyanyi dan melihat video atau animasi. Peranan teknologi informasi untuk pembelajaran membaca bagi anak usia dini, dengan membuat animasi berbagai bentuk huruf, angka, hewan, benda dan lain-lainnya dengan tujuan agar dia dengan tidak sadar selalu belajar dan proses itu tidak akan mengganggu kesenangannya.

Pendidikan usia dini merupakan pendidikan yang diberikan kepada anak sejak usia $0-6$ tahun. Usia dini merupakan usia emas untuk menyerap berbagai informasi. Namun oranghua dan tenaga pendidik harus memberikan materi yang dekat dengan kehidupan dan lingkungan anak yang terrefleksi dalam kegiatan pernbelajaran yang menyenangkan.

Dengan adanya Sofhvare Education untuk pembelajaran cara membaca anak usia dini ini dihurapkan dapat mendukung pembelajaran dengan penyajian yang menyesuaikan cara anak usia dini belajar (bermain sambil belajar).

Model yang digunakan untuk menggambarkan bentuk hubungan perilaku dalam penerimaan Software Education untuk pembelajaran cara membaca adalah dengan menggunakan model TAM (Technology Acceptance Model) yang akan dianalisis dengan menggunakan software AMOS.

\subsection{Identifikasi Masalah}

Setelah mengetahui kenyataan mengenai perkembangan teknologi khususnya di bidang Teknologi Informasi, maka penulis mengidentifikasi adanya hal-hal yang melatarbelakangi penulisan penelitian ini scbagai masalah penelitian, yaitu:

a. Apa saja faktor-fakior yang saiing berhubungan dan berpengaruh terhadap tingkat penerimaan Software Education cara membaca anak usia dini pada sekolah PAUD di Bandar Lampung ?

b. Bagaimana bentuk model penerimaan sebuah Software Education cara membaca anak usia dini yang akan diterapkan di beberapa sekolah PAUD di Bandar Lampung ?

c. Bagaimana hubungan kausal antara faktor-faktor yang mempengaruhi penerimaan Sofiware Education cara membaca anak usia dini ?

\subsection{Ruang Lingkup Masalah}

Ruang lingkup permasalahan dibatasi tentang kajian faktor-faktor penerimaan Software Education cara membaca anak usia dini bagi para guru dan orang tua murid di sepulah (10) sekolah PAUD di Bandar Lampung.

\subsection{Rumusan Masalah}

Terkait dengan berbagai masalah dan penggunaan Softreare Education di sekolah PAUD, maka numusan permasalahan yang menjadi dasar untuk melakukan penelitian ini, yaitu :

a. Bapamana perlunya meneliti faktor: faktor yang mempengaruhi terhadap penerimann Sofiware Education cara membaca anak usia dini di sekolah PAUD sehingga dapat diketahui 
permasalahan-permasalahan dalam proses penerapan teknologi informasi tersebut?

b. Bagaimana mengetahui model penerimaan Software Education cara membaca anak usia dini di sekolah PAUD?

\subsection{Tujuan Penelitian}

a. Untuk mengetahui faktor-faktor yang mempengaruhi tingkat pencrimaun pengguna terhadap Software Edtucation cara membaca anak usia dini.

b. Untuk mengetahui bagaimana model penerimaan pengguna Software Education cara membaca anak usia dini yang diterapkan pada sekolah PAUD di Bandar Lampung

\subsection{Manfaat Penelitian}

Penelitian ini dihurapkan dapat membantu sekolah PAUD untuk meningkatkan penerimaan teknologi melalui penggunaan Sofhvare Education cara membsca anak usia dini untuk membantu user yaitu anak dalam proses pembelajaran

\section{LANDASAN TEORI}

\subsection{Penerimaan Teknologi Informasi}

(Iqbaria, 1994;p83) menyatakan bahwa, secara individu maupun kolekif penerimaan teknologi dapat dijelaskan dari variasi pengeumaan suatu sistem, karena diyakini bahwa penggunan suatu sistem yang berbasis Tl dapat meningkatkan kinerja individu atau kinerja organisasi. Untuk mengetahui indikator penerimaan $\mathrm{TI}$, secara umum diketahui bahwa penerimann $\mathrm{TI}$ dapat dilihat dengan adanya indikator penggunaan sistem dan frekuerisi penggunaan komputer, atau dari aspek kepuasan pengguna dan ada juga yang menjadikan penggunaan sistem sebagai indikator utama penerimaan teknologi oleh pengguanana.

\subsection{Technology Acceptance Model (TAM)}

Technology Accepiance Model (TAM) pertama kali dikembangkan oleh Davis tahun 1989. Dalam penelitian Teknologi Informasi (TI), TAM menupakan model yang paling banyak digunakan menurut (Iqbaria, 1997:p/20), (Adam, 1992:p43) dan (Chin, 1995:p57), karena model ini sederhana dan mudah untuk diterapkan. TAM diadaptasi dari Theory of Reasoned Action (TRA) yang dikembangkan olch Fishbein, yaitu teori tindakan yang beralasan dengan satu premis bahwa reaksi dan persepsi seseorang terhadap sesuatu hal, akan menentukan sikap dan perilaku orang tersebut.

Model TAM menjelaskan perilaku pengguna komputer, yaitu berlandaskan pada kepercayaan (beliefe), sikap (attitude), niat (mtention), dan hubungan perilaku pengguna (user behavior relationship). Tujuan model ini untuk menjelaskan faktor-faktor utama dari perilaku penggunaan TI. Model TAM secara lebih terperinei menjelaskan penerimaan TI dengan dimensi-dimensi tertentu yang dapat mempengaruhi dengan mudah diterimanya $\mathrm{TI}$ oleh pengguna. Model TAM menempatkan faktor sikap dari tiap-tiap perilaku pengguna dengan daa variabel yaitu kemanfaatan (usefilmess) dan kemudahan penggunaan (ease of use). Kedua variabel tersebut dapat menjelaskan aspek keprilakuan pengguna (Davis, 1989:p97).

\subsubsection{Perceived Usefulness (Kemanfaatun)}

Menurut (Davis, 1989:p77) dan (Adam, 1992:p69), Kemanfaatan (wsefulness) diartikan sebagai suatu ukuran kepercayaun seseorang terhadap penggunaan sesuatu untuk dapat meaingkatkan prestasi kerja orang yang menggunakannya. Menurut (Thompson, 1991:p90), kegunaan TI merupakan manfaat yang diharapkan olch pengguna $T 7$ untuk dapat melaksanakan tugasnya, pengukurannya didasarkan pada frekuensi penggunaan dan keragaman aplikasi yang dijalankan. (Chin, 1955.p46) memberikan beberapa dimensi tentang kegunaan $\mathrm{TI}$, dimana kegunaan tersebut dibagi kedalam dua kategori, yaitu :

a. Kegunaan dengan estimasi satu faktor

b. Kegunaan dengan estimasi dua faktor (kegunaan dan efektivitas).

Kegunaan dengan satu faktor meliputi : 
a. Menjadikan pekerjaan lebih mudah

b. Bermanfaat

c. Menambah produktivitas

d. Mempertinggi efektivitas

c. Mengembangkan kinerja pekerjaan

Sedangkan kegunaan dengan estimasi dua faktor meliputi dimensi-dimensi, antara lain:

a. Kegunaan meliputi dimensi menjadikan pekerjaan lebih mudah dan bermanfaat, menambah produktivitas

b. Efektivitas meliputi dimensi ; mempertinggi efektivitas, mengembangkan kinerja pekerjaan

\subsubsection{Perceived Ease of Use (Kemudahan)}

(Davis, 1989;p61) mendefinisikan kemudahan penggunaan (ease of usg) sebagai suatu ukuran bahwa seseorang percaya bahwa komputer dapat dengan mudah dipahami Menurut (Adam, 1992.p87), menyatakan bahwa intensitas penggunaan dan interaksi antar pengguna (user) dengan sistem dapat menunjukkan kemudahan penggunaan.

(Davis, 1989:p93), memberikan beberapa indikator kemudahan penggunaan teknologi informasi, meliputi:

a. Komputer sangat mudah dipelajari

b. Komputer mengerjakan dengan mudah apa yang diinginkan oleh pengguna

c. Keterampilan pengguna dapat bertambah dengan menggunakan komputer

d. Komputer sangat mudah untuk dioperasikan

\subsection{AMOS}

AMOS (Analysis of Moment Structure) merupakas salah satu program atau software yang digunakan untuk mengistemasi model pada model persamaan struktural (SEM) (Ghozali, 2004:p95), AMOS mengimplementasikan pendekatan yang umum untuk analisa data pada model persamaan struktural yang menjelaskan analisa struktur kovarians, atau carusal modefing. Pendekatan ini meliputi kasus khusus banyak teknik konvensional terkenal, mencakup model linier yang umum dan analisis faktor umum (Smallwaters, 2006.p843). Saat ini software AMOS merupakan soffware yang dapat diandalkan dalam menyelesaikan permasalahan sosial karena kemampuannya dalam mengukur variabel yang bersifat laten atau tidak dapat diukur secara langsung tetapi dapat diukur melalui indikatornya.

\subsection{Software Education Cara Membaca}

Software Education Cara Membaca merupakan salah satu program interaktif yang untuk mendukung proses pembelajaran khususnya belajar membaca untuk anak usia dini, disertai dengan gambar, animasi, musik, dan suara.

\subsection{Teknologi}

Definisi teknologi dalam kamus umum Bahasa Indonesia yang disusun oleh W.J.S Poerwadarminta ialah ilmu teknik, pengetahuan tentang teknik. Definisi Produk teknologi adaluh hasil dari sebuah teknologi yang telah diciptakan.

Tujuan Teknologi adalah untuk mempermudah menuju manusia agar dapat hidup lebih myaman. Hasil dari teknologi yang berupa produk dapat dimanfaatkan untuk kegiatan pembelajaran anak usia dini.

\subsection{Pendidikan Anak Usia Dini (PAUD)}

Pengertian pendidikan anak usia dini berdasarkan Undang-undang No. 20 Tahun 2003 bahwa pendidikan anak usia dini adalah suatu upaya pembinaan yang ditujukan bagi anak sejak lahir sampai dengan usia enam tahun yang dilakukan melalui pemberian rangsangan pendidikan untuk membantu pertumbuhan dan perkembangan jasmani dan tohani agar anak dapat memiliki kesiapaa dalam memasuki pendidikan lebih lanjut.

Menurut Dra. Nani Susilawati (Staf Pengajar FISIP USU), tujuan PAUD adalah membantu mengembangkan seluruh potensi dan kemampuan fisik, intelektual, emosional, moral dan agama secan optimal dalam lingkungan pendidikan yang kondusif, demokratis dan kompetitif.

Pentingnya PAUD :

a PAUD sebagai titik sentral strategi pembangunan sumber daya manusia dan sangat fundamental. 
b. PAUD memegang peranan penting dan menentukan bagi sejarah perkembangan anak selanjutnya, sebab merupakan pondasi dasar bagi kepribadian anak.

c. Merupakan masa Golden Age (usia keemasan). Dari perkembangan otak manusia, maka tahap perkembangan otak pada anak usia dini menempati posisi yang paling vital yakni $80 \%$ perkembangan anak.

Cerminan diri untuk melihat keberhasilan anak dimasa mendatang. Anak yang mendapatkan layanan baik semenjak usia $0-6$ tahun memiliki harapan lebih besar untuk meraih keberhasilan dimasa mendatang. Sebaliknya anak yang tidak mendapatkan pelayanan pendidikan yang memadai membutuhkan perjuangan yang cukup berat untuk mengembangkan hidup selanjutnya.

\subsection{Kerangka Pemikiran}

Penelitian ini merupakan salah satu penelitian lanjutan yang dikembangkan dari teon TAM yang diperkenalkan Davis pada tahun 1989 yang menguji dua faktor penerimaan teknologi yaitu Penceived Ease of Use (PEOU) dan Perceived Usefuiness (PU). Kerangka pemikiran yang dijadikan landasan pemikiran adalah modifikasi dari penelitian TAM sebelumnya, yaitu menggunakan model yang mentiadakan faktor ekstemal, karena menurut penelitian sebelumnya, diketahui bahwa Ekstemal variabel seperti karakteristik sistem dan karakteristik pengguna dapat diabaikan karena selanjutnya diketahui bahwa meskipun memiliki pengaruh, faktor eksternal dingggap tidak signifikan dalam TAM (Milchram, 2003 : p40).

Model TAM yang digunakan dalam penelitian yang dilakukan saat ini tergambar pada model berikut:

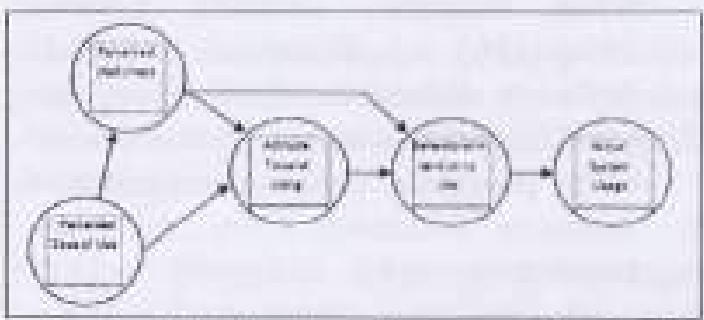

Gambar 1. Technology Acceptance Model (TAM)

\section{Perceived Ease of Use (PEOU)}

Persepsi kemudahan penggunaan didefinisikan sebagai sebagai suatu ukuran dimana seseorang percaya bahwa komputer dapat dengan mudah dipahami (Davis, 1989 : p985). Beberapa indikator kemudahan penggunaan teknologi informasi (Davis, 1989 : p985) meliputi:

a. Komputer sangat mudah dipelajari

b. Komputer mengerjakan dengan mudah apa yang diinginkan oleh pengguna

c. Keterampilan pengguna dapat bertambah dengan menggunakan komputer

d. Komputer sangat mudah untuk dioperasikan

\section{Perceived Usefulness (PU)}

Persepsi kemanfaatan didefinisikan sebagai suatu ukuran dimana kepercayaan seseorang terhadap penggunaan sesuatu akan dapat meningkatkan prestasi kerja orang yang menggunakannya (DAVIS, 1989 ; p985).

Beberapa dimensi tentang kegunaan $\mathrm{TL}$, dimana kegunaan tersebut dibagi kedalam dua kategori, yaitu: 1) kegunaan dengan estimasi satu faktor, dan 2) kegunaan dengan estimasi dua faktor (Kegunaan dan efektivitas) (Todd, 1995 : p326) pada (Nasution, 2004 p217).

Kegunaan dengan satu faktor meliputi :

3. Menjadikan pekerjaan lebih mudah

b. Bermanfaat

c. Menambah produktivitas

d. Mempertinggi efektivitas

c. Mengembangkan kinerja pekerjaan

Sedangkan kegunaan dengan estimasi dua faktor meliputi dimensi-dimensi;

a. Kegunaan meliputi dimensi: menjadikan pekerjaan lebih mudah. bermanfaat, menambah produktivitas

b. Efektivitas meliputi dimensi: mempertinggi efektivitas, mengembangkan kinerja pekerjaan

\section{Attitude Toward Using (ATU)}

Attitude towand nsing the system yang dipakai dalam TAM didefinisikan sebagai suatu 
tingkat penilaian yang dirasakan (negatif atau positif) yang dialami sebagai dampak bila seseorang menggunakan suatu teknologi dalam pekerjaannya (Davis, 1989 : p 985 ).

Peneliti lain menyatakan bahwa faktor sikap (attitude) sebagai salah satu aspek yang mempengaruhi perilaku individual. Sikap seseorang terdiri atas komponen kognisi (cognimve), afeksi (affective), dan komponenkomponen yang berkaitan dengan perilaku (behavioral components). (Thompson 1991 : p125) pada (Nasution 2004 :p217)

\section{Intention to Use (ITU)}

Intention to Use adalah kecenderungan tingkah laku untuk mengetahui seberapa kuat perhatian seorang pengguna untuk menggunakan sebuah teknologi

Tingkat pengguaaan sebuah teknologi komputer pada seseorang dapat diprediksi dengan akurat dari sikap perhatiannya terhadap teknologi tersebut, misalnya keinginanan menambah peripheral pendukung, motivasi untuk tetap menggunakan, serta keinginan untuk memotivasi pengguna lain ([DAVIS 1989\%, 985). Peneliti selanjutnya menyatakan bahwa sikap perhatian untuk menggunakan adalah prediksi yang baik untuk mengetahui Actual Usage (Malhotra, 1999 : p9).

\section{Actual System Usage (ASU)}

Perilaku pemakaian nyata pertama kali dikonsepkan dalam bentuk pengukuran frekuensi dan durasi waktu terhadap penggunaan sebuah teknologi (Davis, 1989 : p985).

Seseorang akan puas menggunakan sistem jika mereka meyakini bahwa sistem tersebut mudah digunakan dan akan meningkatkan produktifitas mereka, yang tercermin dari kondisi perilaku nyata pemakai (lqubaria 1997 pada (Natalia, $2003 \div$ p12).
Tabel 1. Kerangka Pemikiran

\begin{tabular}{|c|c|c|}
\hline$n=1$ & Vartaful Latos & Isaliveter \\
\hline A & 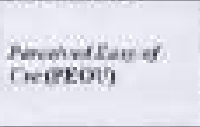 & 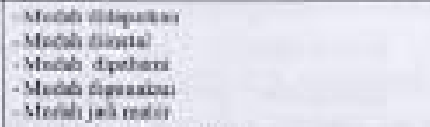 \\
\hline 1 & 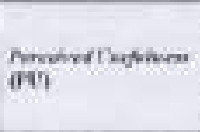 & 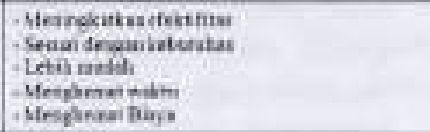 \\
\hline 1. & 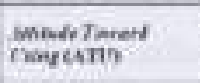 & 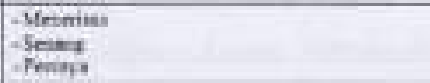 \\
\hline+ & 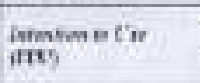 & 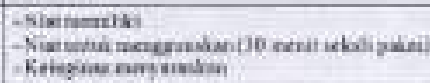 \\
\hline A & 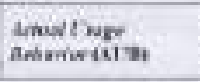 & 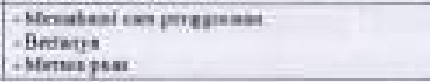 \\
\hline
\end{tabular}

\subsection{Hipotesa}

Hipotesis-hipotesis khusus pada penelitian ini adalah :

a. Diduga Persepsi Kemudahan menggunakan Software Education untuk Pembelajaran Cara Membaca berpengaruh terhadap Persepsi Kemanfaatan Persepsi Kemanfaatan (Percieved Usefulness:PU). Semakin mudah Soffware Education Cara Membaca untuk digunakan maka semakin tinggi tingkat kemanfaatannya.

b. Diduga Persepsi Kemanfaatan Software Educalion Cara Membaca (Percieved Usefuiness/PU) berpengaruh terhadap Sikap Pengguna (Attitude Toward Using/ATU). Semakin tinggi tingkat kemanfaatan Software Education Cara Membaca maka semakin positif sikap pengguna dalam menggunakan Soffware Education Cara Membaca tersebut.

c. Didaga Persepsi Kemudahan menggunakan Software Education Cara Membaca (Perceived Ease of UsePEOU) berpengaruh terbadap Sikap Pengguna (Atutude Toward Using/ATU). Semakin mudah Software Education Cara Membaca untuk digunakan maka semakin positif sikap pengguna dalam menggunakan Sofhvare Educalion Cara Membaca tersebut. 
d. Diduga Sikap Pengguna Software Education Cara Membaca (Aititude Toward Using/ATU) berpengaruh terhadap Perilaku Pengguna (Intention to Use/TU). Semakin positif sikap pengguna dalam menggunakan Software Education Cara Membaca maka semakin meningkat niat untuk menggunakannya

e. Diduga Persepsi Kemanfaatan Soffware Education Cara Membaca Percieved Usefulness/PU) berpengaruh terhadap Perilaku Pengguna (Intention to UseITU). Semakin tinggi tingkat kemanfaatan Software Education Cara Membaca maka semakin meningkat niat untuk menggunakannya.

f. Diduga Perilaku Pengguna Aplikasi Pembelajaran Cara Membaca (Intention to Use/TU) berpengaruh terhadap Pemakaian Nyata (Actual Sysiem Usage/ASU). Semakin tinggi niat untuk menggunakan Sofware Education Cara Membaca maka semakin positif perilaku dalam menggunakarunya.

\section{METODE PENEUITIAN}

\subsection{Analisa Kebutuhan}

\subsubsection{Jenis Penelitian}

Penelitian ini termasuk ke dalam jenis penelitian Explaratory, yaitu penelitian yang berisi pembuktian hipotesa yang dibangun melalui teori dengan pendekatan Technology Acceptance Model (TAM), diuji menggunakan perangkat lunak AMOS 7.0.

\subsubsection{Populasi dan Sampel Penelitian}

Metode yang digunakan untuk mendapatkan data empiris melalui kuesioner berskala Semantik diferensial. Dengan metode ini diharapkan dapat diperoleh rating penerimaan pengguna Software Education Cara Membaca Anak Usia Dini di sepuluh (10) sekolah PAUD di Bandar Lampung.

Populasi pengguna teknologi pembelajaran cara membaca untuk anak usia dini adalah guru dan wali murid. Jumlah guru dan wali murid yang hendak dijadikan responden adalah sebanyak 120 responden, dimana $60 \%$ adalah guru dan $40 \%$ adalah orangtua murid.

Metode penarikan sampling dilakukan dengan menggunakan penarikan sampling purposive yaitu penarikan sampling dengan pertimbangan tertentu yang didasarkan pada kepentingan atau tujuan penelitian.

Terdapat dua cara penarikan sampel purposive, yaitu convenience (berdasarkan keinginan peneliti) dan judgement sampling (berdasarkan penilaian terhadap karakteristik yang ada).

Tahel 2. Jumlah Angxota Populast clam Sampel Peneinian

\begin{tabular}{|c|c|c|}
\hline Me. & Nixissekot & $\begin{array}{l}\text { Fuspra. } \\
\text { clrang }\end{array}$ \\
\hline 1 & TK.SNH TILABN & 12. \\
\hline 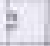 & TK XENTAEI & 17 \\
\hline 2 & TK FUTR MILAH & 12 \\
\hline 4 & TK ITRAMBsastI & 12 \\
\hline 5. & TK TLXAS KARYA & it \\
\hline 6. & 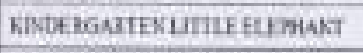 & 12 \\
\hline 7 & 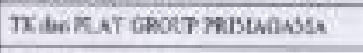 & 12 \\
\hline 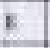 & TE savper nuthe & 12 \\
\hline ?. & TE ARzALDAII & 12 \\
\hline 16 & 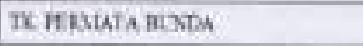 & H \\
\hline
\end{tabular}

\subsubsection{Penelitian Perpustakaan}

Dimaksudkan untuk mendapatkan data atau fakta yang bersifat teoritis yang bethubungan deagan penelitian ini, yang diperoleh dengan cara mempelajari literatur-literatur, jurnaljurnal penelitian, bahan kuliah dan sumbersumber lain yang ada hubungannya dengan permasalahan yang penulis bahas.

\subsubsection{Kuesioner}

Merupakan pertanyaan-pertanyaan yang dibuat oleh penulis untuk mengetahui bagaimana pengaruh antara variabel Persepsi Kemudahan Menggunakan (Perceived Ease of Use/PEOU). Persepsi Kemanfaatan (Percened UsefulnessPU), Sikap Pengguna (Attitude Toward Using $A T U$ ). Perilaku Pengguna (Behaviaral Intention To Use MUJ) dan Perilaku Nyata (Acnal System Usage/ASU) 
dari responden terhadap pengguna Software Education Cara Membaca Anak Usia Dini.

\subsubsection{Perancangan Penelitian}

\subsubsection{Konstruk eksogenous (Exogenous Constructs)}

Konstruk ini dikenal sebagai sources variables atau independen variabel yang tidak diprediksi oleh variabel yang lain dalam model. Pada Penelitian ini konstruk eksogenous meliputi: Perceived Ease of Use (PEOU), menupakan suatu tingkatan dimana seseorang percaya bahwa sebuah teknologi dapat dengan mudah dipahami.

\subsubsection{Konstruk Endogen}

\section{(Endogenous Constructs)}

Adalah faktor-faktor yang diprediksi oleh satu atau beberapa konstruk. Konstruk endogen dapat memprediksi satu atau beberapa konstruk endogen lainnya, tetupi konstruk endogen hanya dapat berhubungan kausal dengan konstruk endogen. Pada penelitian ini konstruk endogen meliputi Perceived Usefulness (PU). Attitude Towand Using (ATU), Behavioral Intention To Use (TTU) dan Actual System Usage (ASU)

Skala pengukuran semua variabel bebas dan variabel tak bebas yang digunakan dalam penelitian ini adalah skala Semantik Diferensial, yakni skala pengukuran yang dapat memberikan penjelasan mengenai kategon, peringkat, jarak dan perbandingan.

Jenis data yang digunakan adalah data primer yaitu data mentah yang dikutip dan diolah langsung oleh penulis dari responden individual. Dalam hal ini berupa kuesioner yang penulis sebarkan kepada para staff, karyawan dan manajemen yang memenuhi kriteria-kriteria yang telah ditetapkan. Untuk mengantisipasi tingkat pengembalian kuesioner agar relatif tinggi, kuesionerkuesioner tersebut diserahkan secara langsung kepada responden.

\subsection{Teknik Analisis}

\subsubsection{Analisis Deskriptif}

Tujuan analisis ini memberikan gambaran atau detesis suanu data berupa rata-rata, standar deviasi, variance, maksimum, minimum, kurtosis (puncak dari distribusi data), dan skewness (kemencengan distribusi data).

\subsubsection{Metode Olah Data Dengan Structural Equation Model (SEM)}

\section{Langkah-Langkah Dalam SEM}

\section{a. Pengembangan model berbasis teori}

Tujuan dari analisis ini untuk mengetahui bagaimana audit. Konstruk (faktor) dan dimensi-dimensi yang akan diteliti dari model teoritis diatas akan diuraikan dalam bagan berikut ini:

Toubei 3. Bungunam, Meciei Teorita

\begin{tabular}{|c|c|c|}
\hline VARGARELAFS & DCMESER LOSSTACK & $\begin{array}{l}\mathrm{TH} \\
\mathrm{rts}\end{array}$ \\
\hline 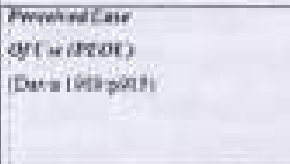 & 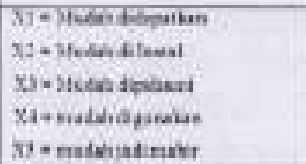 & $\begin{array}{l}T \\
1 \\
1 \\
1 \\
1\end{array}$ \\
\hline 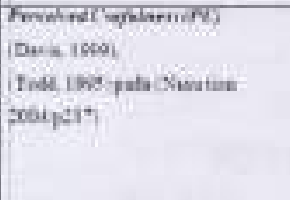 & 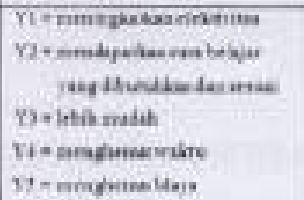 & $\begin{array}{l} \\
1 \\
1 \\
1 \\
1 \\
1\end{array}$ \\
\hline 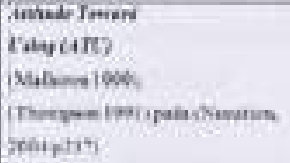 & 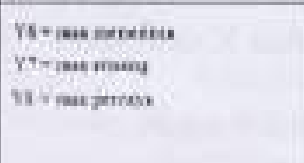 & 1 \\
\hline 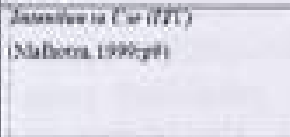 & 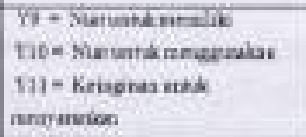 & $\begin{array}{l}1 \\
1 \\
1\end{array}$ \\
\hline 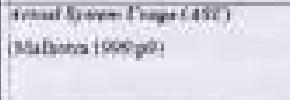 & 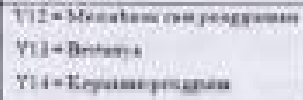 & $\begin{array}{l}1 \\
1 \\
1\end{array}$ \\
\hline
\end{tabular}

\section{b. Pengembangan Diagram Alur (Path diagram)}

Setelah dibangun model teoritis, kemudian digambarkan sebuah path diagram. Biasanya diketahui bahwa hubungan-hubungan kausal dinyatakan dalam bentuk persamaan. Tetapi dalarn SEM (dalam operasi AMOS) hubungun kausalitas cukup digambarkan dalam sebuah path diagram. Selanjutnya, bahasa program akan mengkonversikan gambar menjadi persamaan, dan persamaan menjadi estimasi. 
Tujuan dibuatnya path diagram adalah untuk memudahkan peneliti dalam melihat hubungan-hubungan kausalitas yang ingin diuji. Hubungan antar konstruk dinyatakan dengan anak panah. Anak panah yang mengarah dari suatu konstruk ke konstruk lain menunjukkan hubungan kausal

Pada penelitian ini, path diagram yang dibangun seperti yang terlihat pada gambar berikut:

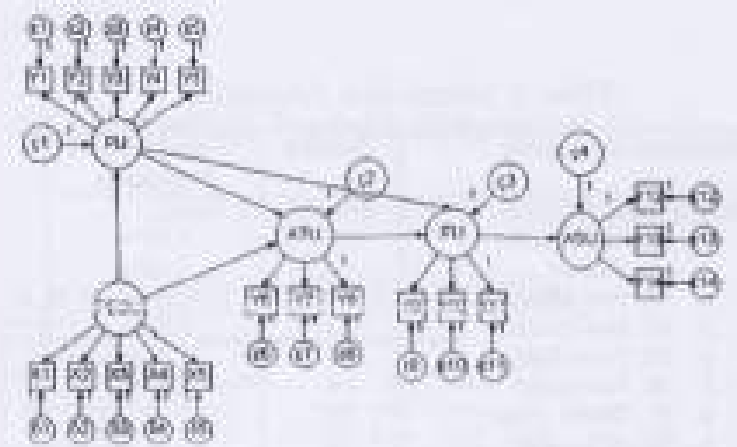

Gambar 2

Dagram Madel Variabel Penelinian ini

\section{c. Konversi diagram alur ke dalam persamaan}

Setelah langkah 1 dan 2 dilakukan, peneliti dapat memulai mengkonversi spesifikasi model tersebut kedalam rangkaian persamaan, diantaranya adalah:

1. Persamaan-persamaan Struktural (Structural Equations)

Persamaan ini dinumuskan untuk menyatakan hubungan kausalitas antar berbagai konstuk, dengan membentuk model pengukuran variabel laten eksogenous dan endogenous, bentuk persamaannya antara lain:

$\mathrm{PU}=\gamma 11 \mathrm{PEOU}+\varsigma 1$

$\mathrm{ATU}=\gamma 21 \mathrm{PEOU}+\beta 21 \mathrm{PU}+\mathrm{c}^{2}$

$\mathrm{ITU}=\beta 32 \mathrm{ATU}+\beta 3 \mathrm{IPU}+\beta^{3}$

ASU $=\beta 431 T U+\varsigma 4$

2. Persamaan spesifikasi model pengukuran (Measurement Model)

Peneliti menentukan variabel mana mengukur konstruk mana, serta serangkaian matriks yang menunjukkan korelasi yung dihipotesakan antar konstruk atau variabel. Bentuk persamaan indikator variabel laten eksogenous dan indikator variabel laten endogenous antara lain :

Persamaan pengukuran indikator variabel eksogenous

$$
\begin{aligned}
& X 1=\lambda 11 \text { PEOU }+81 \\
& X 2=\lambda 21 \text { PEOU }+82 \\
& X 3=\lambda .31 \text { PEOU }+83 \\
& X 4=\lambda .41 \text { PEOU }+84 \\
& X 5=\lambda .51 \text { PEOU }+85
\end{aligned}
$$

Persamaan pengukuran indikator variabel endogenous

$$
\begin{aligned}
& y 1-\lambda 11 P U+\varepsilon 1 \\
& y 2=\lambda 21 P U+\varepsilon 2 \\
& y 3=\lambda 31 P U+\varepsilon 3 \\
& y 4=\lambda .41 P U+\varepsilon 4 \\
& y 5=\lambda .51 P U+\varepsilon 5 \\
& y 6=\lambda .62 \mathrm{ATU}+\varepsilon 6 \\
& y 7=\lambda 72 \mathrm{ATU}+\varepsilon 7 \\
& y 8=\lambda .82 \mathrm{ATU}+\varepsilon 8 \\
& y 9=\lambda 931 T U+\varepsilon 9 \\
& y 10=\lambda 103 \mathrm{ITU}+\varepsilon 10 \\
& y 11=\lambda 113 \mathrm{ITU}+\varepsilon 11 \\
& \text { y12 }=\lambda 124 \mathrm{ASU}+\varepsilon 12 \\
& \text { y13 }=\lambda 134 \mathrm{ASU}+\varepsilon 13 \\
& \mathrm{y} 14=\lambda 144 \mathrm{ASU}+\varepsilon 14
\end{aligned}
$$

\section{d. Memilih matriks input dan Estimasi model}

Dalam SEM hanya menggunakan matriks varians atau kovarians atau matriks korelasi sebagai data input untuk keseluruhan estimasi yang dilakukannya. Matriks kovarians digunakan karena ia memiliki keunggulan d alam menyajikan perbandingan yang valid antara populasi yang berbeda dengan sampel yang berbeda Matriks kovarians umumnya lebih banyak digunakan dalam penelitian mengenai hubungan seperti direkomendasikan oleh Baumgather dan Homburg (1996), sebab standar error yang dilaporkan dari berbagai penelitian umumnya menunjukkan angka yang kurang akurat bila matriks korelasi digunakan sebagai input.

Disarankan agar peneliti menggunakan matriks kovarians/varians pada saat pengujian teoritis sebab kovarians/varians lebih memenuhi asumsi-asumsi metodologi dan merupakan bentuk data yang lebih sesuai untuk meavalidasi hubungan-hubungan kausalitas (Hair 1996.p1 12). 
Untuk melakukan estimasi dari model yang dikembangkan dan input data yang dipilih, peneliti menggunakan AMOS.16 dengan teknik estimasi sebagai berikut:

1. Maximum Likelihood Estimation (ML)

2. Generalized Least Square Estimation (GLS)

3. Unweighied Least Square Estimotion (UISS)

4. Scale Free Least Square Estimation (SLS)

5. Asymptotically Distribution-Free Extimation $(A D F)$

\section{e. Kemungkinan munculnya masalah identifikasi}

Ketika akan melakukan estimasi pada model kausal ini, salah satu masalah yang akan dihadapi adalah masalah identifikasi. Problem identifikasi pada prinsipnya adalah problem mengenai ketidakmampuan dari model yang dikembangkan untuk menghasilkan estimasi yang unik.

\section{f. Evaluasi kriteria Goodness of Fit}

Tindakan yang dilakukan adalah mengevaluasi apakah data yang digunakan dapat memenuhi asumsi-asumsi SEM.

\section{PEMBAHASAN}

\subsection{Pengelompoksn Data}

\subsubsection{Data Profil Responden}

Responden yang menjawab kuesioner sebanyak 120 crang, kuesioner tersebut disebarkan secara langsung. Data Profil responden yang menjadi obyek penelitian ini dapat dilihat pada Tabel berikut :

Tabel 4. Respouden penelitian

\begin{tabular}{|c|c|c|}
\hline Xarfitasi Renpostra & Junialy & G deri uplarat revesde \\
\hline \multicolumn{3}{|l|}{ Gove } \\
\hline 1. Ix San telatan & 6 & $899 \%$ \\
\hline b D S Shiar & 6 & $8.390=$ \\
\hline E D. Teri Arizat & 6 & $8,33 \%$ \\
\hline d. TK. Fith Gasis 1 & 3 & $11.11 \%$ \\
\hline f. TK Juas Kary & $y$ & $1 \leqslant 5 \%$ \\
\hline 5. TK- Minapana & 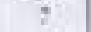 & Q.71\%. \\
\hline 8. TK Sandis Pua & a. & il.11\%" \\
\hline f. Th ar Radas & 3 & Bus"s \\
\hline I TK. Penuas Desdi & 3 & $11.13 \%$ \\
\hline IK Fital farati II & क & 3915 \\
\hline 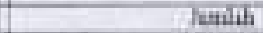 & 7 & 1001 \\
\hline 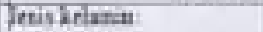 & & \\
\hline Labiala & 4 & $3,33 \%$ \\
\hline Feierapuin & te & $51.5=6$ \\
\hline Enlih & 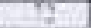 & $10 \%$ \\
\hline
\end{tabular}

Tabel 5. Respanden Penelinam

\begin{tabular}{|c|c|c|}
\hline Kladifikai keyposen & Joxiah & $\begin{array}{c}\text { ". dari selarih } \\
\text { respaded }\end{array}$ \\
\hline \multicolumn{3}{|l|}{ Crangua Straid } \\
\hline a. IK San Telatar & 4 & $8,33 \%$ \\
\hline b. TK. Slestant & 3 & $1,35 \%$ \\
\hline c. TK Putn Arizah & t & $18: 3$, \\
\hline e. TK Nuratami 1 & 3 & $153 \%$ \\
\hline c. TK Tunar Kats & t & $3 ; 53^{3}$ \\
\hline f. TK Pomagamia & 4 & 353, \\
\hline f. TK Sandix hum & 0 & $1: 2 \theta_{8}$ \\
\hline i Th. desaudah & 6 & v214, \\
\hline 1. IK Pemasa fienda & 5 & $2: A_{4}$ \\
\hline f. TK. Fmah Inian II & 4 & $123 t_{0}$ \\
\hline \multicolumn{3}{|l|}{ Jming } \\
\hline $\begin{array}{l}\text { Jensikejamia } \\
\text { Lativio } \\
\text { - Pertrofue }\end{array}$ & $\frac{12}{15}$ & $\begin{array}{l}2 \pi, \\
4 \%,\end{array}$ \\
\hline tortin & If & t5o\% \\
\hline 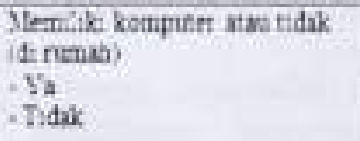 & $\frac{45}{2}$ & 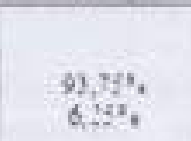 \\
\hline Jumi: & 78 & $100 \%$ \\
\hline
\end{tabular}

Sumber: Olakan Penulis

Pada penelitian ini responden yang paling banyak adalah guru karena guru lah yang bisa mewakili banyak anak dalam mengoperasikan Soffware Education Cara Membaca didalam kelas untuk melakukan pengajaran

\subsection{Hasil Penelitian}

\subsubsection{Analisis Statistik Deskriptif}

Pengujian atau analisa terhadap statistik deskriptif yang memberikan penjelasan berupa nilai mean (rata-rata), standar deviasi, varian, maksimum, range, kurtosis dan skewness dapat dilihat pada Lampiran 1 (statistik deskriptif). 
Dengan melihat Lampiran 1, dijelaskan bahwa data memiliki nilai Valid $\mathrm{N}$ (listwise) dengan tingkat validitas yang baik yaitu sebesar 120 (100\%), demikian pula dengan kriteria lain yang terdapat pada uji statistik deskriptif

\subsubsection{Analisis Statistik Inferensial}

\section{Tabel 5. Aswement of Normality}

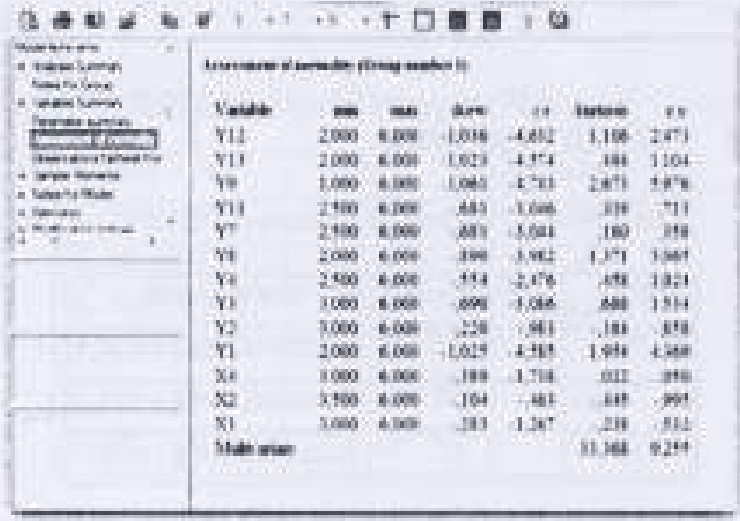

Sebuah distribusi dikatakan normal jika angka c.r skweness atau angka c.r kurtosis ada diantars $-2,58$ sampai $+2,58$. Namun jika angka-angka tersebut berada di bawah $-2,58$ dan diatas +2.58 maka distribusi dikatakan tidak normal.

Berdasarkan nilai c.r (critical rasio) dalam text output di "Assessment of Normality" sebesar 9,255 , sedangkan $9,255>2,58$ yang berarti data tidak normal

\subsubsection{Objek Penelitian}

Tabel 6. Variabel Penelitian yang diobsernasi

\begin{tabular}{|c|c|c|}
\hline THUABR LiTEY & Datrva kassinex & $\begin{array}{c}\text { rtingur } \\
\text { meyr }\end{array}$ \\
\hline 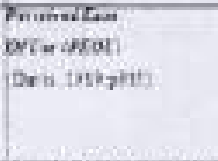 & 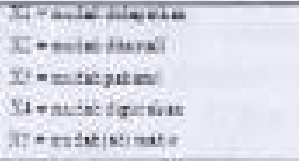 & $\begin{array}{l}7 \\
1 \\
1 \\
1 \\
1\end{array}$ \\
\hline 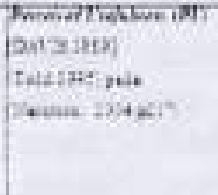 & 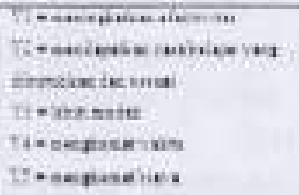 & $\begin{array}{l}1 \\
1 \\
1\end{array}$ \\
\hline 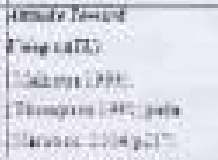 & 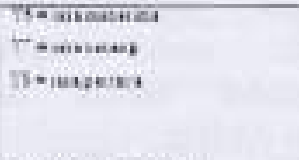 & $\begin{array}{l}7 \\
1 \\
1\end{array}$ \\
\hline 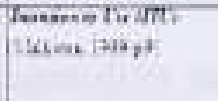 & 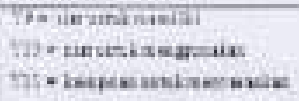 & $\begin{array}{l}7 \\
1 \\
1 \\
1\end{array}$ \\
\hline 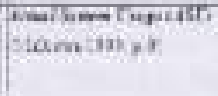 & 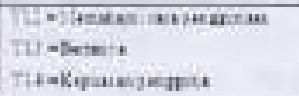 & $\begin{array}{l}1 \\
1 \\
1\end{array}$ \\
\hline
\end{tabular}

\subsubsection{Pengujian Model Berbasis Teori}

Pengujian model berbasis teori dilakukan dengan menggunakan software AMOS Versi 16.0. Berikut ini adalah hasil pengujian model tersebut

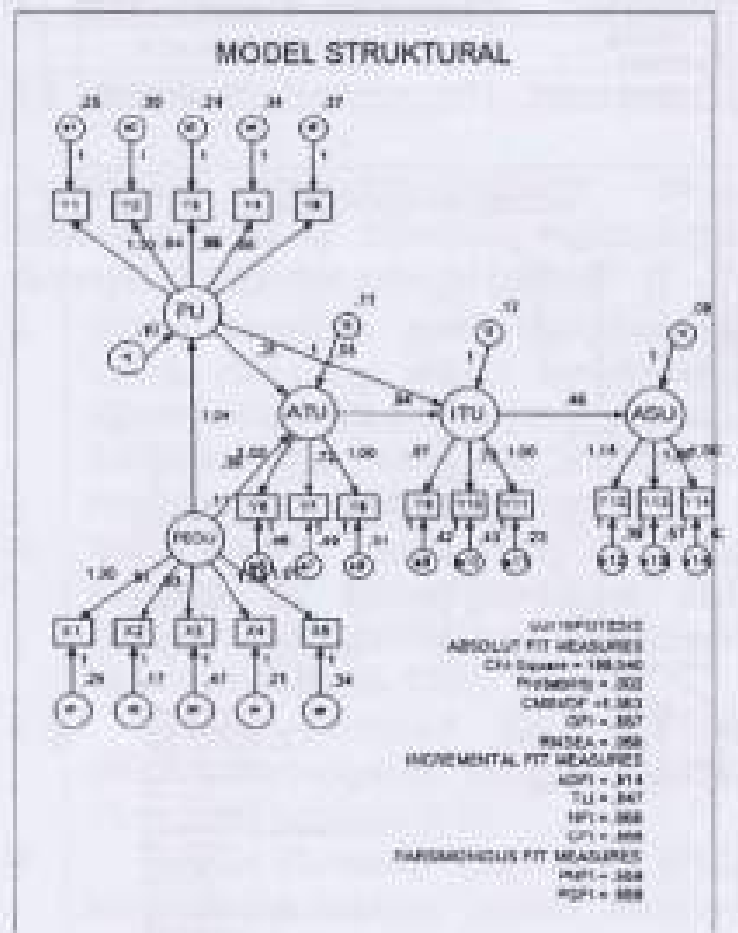

Gambar 3. Hasil Madel Awal Penelitiam

Berdasarkan Gambar 3, diperlihatkan bahwa model teon yang diajukan pada penelitian ini tidak sesuai dengan model populasi yang 
diobservasi, karena diketahui bahwa nilai probability $(\mathrm{P})=0,002$ tidak memenuhi persyaratan karena hasilnya di bawah nilai yang direkomendasikan yaitu $p>0.05$ (Ghozali, 2005 p:83).

Untuk sementara dapat disimpulkan bahwa output model belum memenuhi persyaratan penerimaan $\mathrm{Ho}$, sehingga tidak dapat dilakukan uji hipotesis selanjutnya. Namun demikian, agat model yang diajukan dinyatakan fit, maka dapat dilakukan modifikasi model sesuai dengan yang disarankan oleh AMOS.

Berdasarkan justifikasi teoritis yang telah ada, maka dilakukan modifikasi model dengan asumsi perubahan model struktural harus dilandasi dengan teori yang kuat (Ghozali, 2005 p:71).

\section{Tabel 7. Langkah Modifikasi}

\begin{tabular}{|c|c|c|}
\hline xa & Mutifled & Katrages \\
\hline 1 & 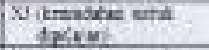 & 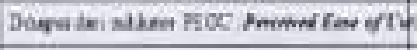 \\
\hline t) & 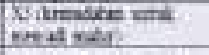 & 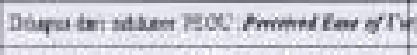 \\
\hline if & Dischos bal & 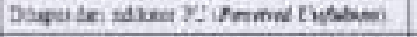 \\
\hline$t$ & Wownense & 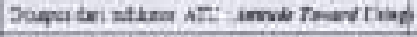 \\
\hline 1 & 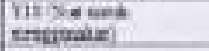 & 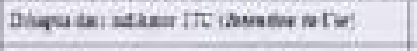 \\
\hline 8 & 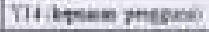 & 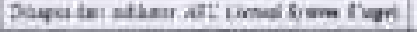 \\
\hline
\end{tabular}

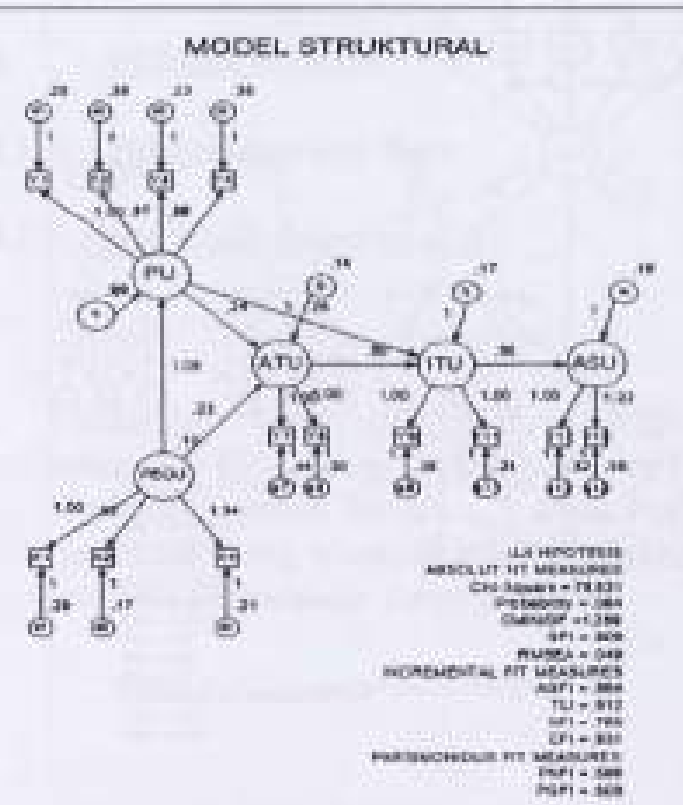

Gambar 4. Hasil Pengujian Model Akhir Penelitian

Tabel 8. Uji Perbandingan Kesesnajan Model

\begin{tabular}{|c|c|c|c|}
\hline Taras Lnowain & $\begin{array}{l}\text { Baist alai } \\
\text { bes }\end{array}$ & $\begin{array}{l}\text { Had } \\
\text { oatel } \\
\text { int }\end{array}$ & Krtanaga \\
\hline \multicolumn{4}{|l|}{ I. thade Fo Beatien } \\
\hline ecz-saxen Nevest & Chats?atal & TSEI & Aar \\
\hline E Pobitase & rant & 10054 & Jak \\
\hline 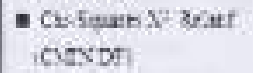 & $\$ 20$ & $13: 9$ & Ber. \\
\hline$=\mathrm{C}^{\prime}$ & 2000 & $7 \% 9$ & $2 x$ \\
\hline$=3051 \mathrm{~A}$ & 7084 & 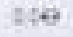 & atak \\
\hline \multicolumn{4}{|l|}{ 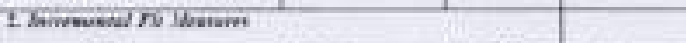 } \\
\hline$=\quad 2 x=I^{2}$ & 200 & TISA & Xarink: \\
\hline * III & teos & 10at? & $34 x$ \\
\hline 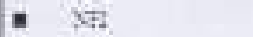 & 250 & 1135: & Stastak \\
\hline$=\mathrm{ct}$ & zeat & $p=51$ & Watgras \\
\hline \multicolumn{4}{|c|}{ 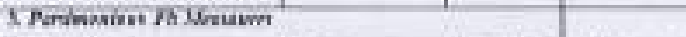 } \\
\hline * $\quad$ xat & 2900 & $0 \geqslant 5$ & 354724 \\
\hline$=70 t:$ & ion & anos & Des \\
\hline
\end{tabular}

4.3 Hasil Pengujian

Tabel 9, Uj Parameser Variabel PEOU

\begin{tabular}{|c|c|c|}
\hline PEOT & Estimate & Krterangan \\
\hline$\$ 1$ & 0560 & Soastruk yasg vatd \\
\hline$\sqrt{52}$ & 0.538 & Koattruk : vang taid \\
\hline$\$ 7$ & 0,702 & Koadtruk yang 12 :d \\
\hline
\end{tabular}

Tabel 10. Uji Parameter Vaniabel PU

\begin{tabular}{|c|c|c|}
\hline$P T$ & Estimate & Keterangan \\
\hline 71 & $0.5+8$ & Koestruk yang va:d \\
\hline T2 & 0.535 & Kasstrik yang vaitd \\
\hline 59 & 0.791 & Ǩostruk yang vato \\
\hline 17 & 0.526 & Konstruk vang ra:d \\
\hline
\end{tabular}

Tabel 12. Uji Parameter Variabel ATU

\begin{tabular}{|c|c|c|}
\hline ATI & Estimatt & Ketrrangan \\
\hline 77 & 0529 & Konsenuk yang fald \\
\hline 15 & $0 \leq 50$ & Konseruk yang ta.1d \\
\hline
\end{tabular}

Tabel 13. UII Parameter Variahel ITU

\begin{tabular}{|c|c|c|}
\hline III & Estimant & Keteranzas \\
\hline 19 & $0.64=$ & Kontruk yang raid \\
\hline V11 & 0.71 & Konstruk yang raidd \\
\hline
\end{tabular}

Tabel 14. Uji Panameter Variabel ASU 


\begin{tabular}{|c|c|c|}
\hline ASC & Estimate & Keterangan \\
\hline Y12 & 0757 & Koostruk vagg vajd \\
\hline 313 & 0576 & Korstruk vagg vaid \\
\hline
\end{tabular}

Tabet Is, Uji Reliabilinas

Gabungun

\begin{tabular}{|c|c|c|}
\hline Yeituritaite & 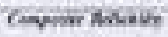 & Tetent Rinewd \\
\hline 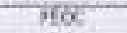 & 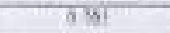 & किस्म \\
\hline 20 & 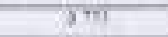 & Ties \\
\hline At: & inil & $7 x$ \\
\hline the & Tas & समत्ब \\
\hline 20 & Th: & Tis: \\
\hline
\end{tabular}

Tahel Ia Hasil Pengujian Hipotesis

\begin{tabular}{|c|c|c|}
\hline Eipatesh & Sig & Havil Bipatคhi \\
\hline E;PEOE-7L; & Q9m & Ta.s. H: \\
\hline 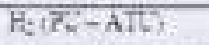 & 0000 & TOSAR: \\
\hline HW1PLOL-ATh) & asts & Tetra H \\
\hline HEIATt-JTh? & 637 & Terima \\
\hline Het? -ATR) & 0.00 & Tot \\
\hline HettI-as' & 2203 & To:alk \\
\hline
\end{tabular}

Berdasarkan Tabel di atas, dapat dijelaskan bahwa:

a. Variabel Perceived Fase of Vise (PEOU) berpengaruh terhadap variabel Perceived Usefulness (PU)

b. Variabel Penceived Usefilness (PU) berpengaruh terhadap variabel Intention to Use (ITU).

c. Variabel Perceived Ease of Use (PEOU) tidak berpengaruh terhadap variabel Aitinude Toward Using (ATU).

d. Variabel Attiude Toward Using (ATU) tidak berpengaruh terhadap variabel Intention to Ulse (ITU)

e. Variabel Perceived Usefulness (PU) berpengaruh terhadap Attitude Toward Using (ATU).

f. Variabel Intention to Use (ITU) berpengaruh terhadap variahel Acnial System Usage(ASU)

\subsection{Interpretasi Model}

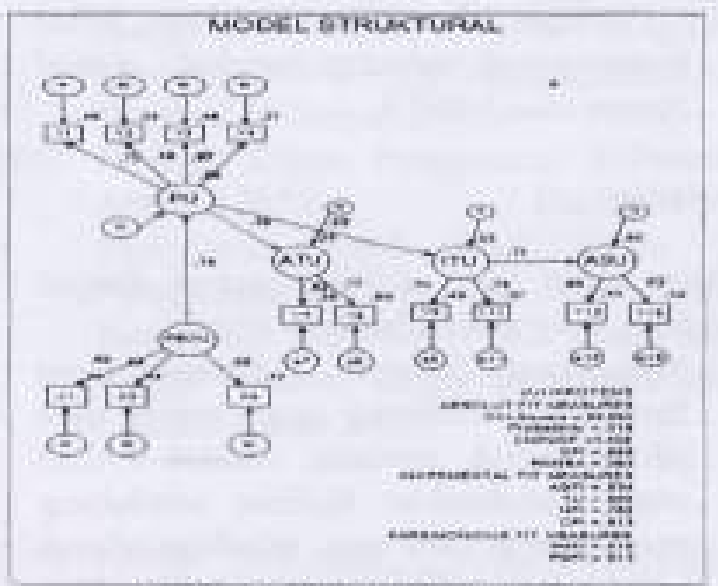

Gambar 5. Model Akhir Penelitian

Berdasarkan model pada gambar 4.3 didapatkan bahwa model pada penelitian ini adalah model TAM (Technology Acceptance Modef) oleh Davis (1989) Variahel yang mempengaruhi penggunaan Software Education Cara Baca pada penelitian ini meliputi PU (Perceived Usefuiness). PEOU (Perceived Easy of Utse). Amitude Toward Using (ATU), Intention to Use (ITU) dan ASU (Actual System Llsage).

\section{SIMPULAN DAN SARAN}

\subsection{Simpulan}

Berdasarkan pengujian-pengujian yang dilakukan terhadap hipotesis, maka dapat disimpulkan hal-hal sebagai berikut :

a. Model penelitian pada penelitian ini adalah mandatory artinya model yang dibuat harus dipakai oleh pengguna atau diwajibkan jadi sikap dan niat untuk menggunakan tidak diperthatikan.

b. Model akhir yang diperoleh pada penelitian ini adalah modifikasi dari model TAM (Technology Acceptance Model) olch (Davis, 1989)

c. Variabel Perceived Ease of Use (PEOU) berpengaruh terhadap variabel Perceived Usefulness (PU)

d. Variabel Perceived Usefulness (PU) berpengaruh terhadap variabel Intention to Use (ITU).

e. Variabel Perceived Usefulness (PU) berpengaruh terhadap Attitude Toward Using (ATU). 
f. Variabel Intention to Use (ITU) berpengaruh terhadap variabel Actual System Usage(ASU).

\subsection{Saran}

Adapun saran yang diajukan sesuai dengan penelitian yang telah dilakukan adalah:

a. Penggunaan Software Education Cara Baca harus didukung secara penuh oleh pihak sekolah terutama sekolah PAUD untuk memberikan fasilitas pendukung pembelajaran cara baca, misalnya adanya berisi beberapa komputer yang dilengkapi dengan speaker dan monitor LCD

b. Software Education Cara Baca, hanus selalu dilakukan pengupdetan selalu dapat menggunakan software versi terbaru yang lebih baik dan menarik dan sesuai untuk unak usia dimi.

c. Untuk pembelajaran dengan menggunakan sofware, pihak manajeman sekolah harus bisa memastikan bahwa guru sudah mempelajari software tersebut atau diadakan pelatihan penggunaan software tersebut terlebih dahulu.

d. Moderating factor untuk the basic structure of user TAM / the factor of interest terdiri dari gender, age, experience, intelectual capacity dan type of techonolgy. Pada penelitian ini moderating factor nya tidak terlalu diperhatikan dan diharapkan pada penelitan selanjutnya moderating factor tersebut harus diperhatikan dengaa baik karena dengan memperhatikan moderating factor hasilnya akan lebih baik dan model yang dihasilkan juga baik

c. Factor contributing user acceptance (independent variable) pada TAM terdiri dari usefulness (perceived). easy of use (perceived), playfulness, subjectiveness, dan facilitating conditions. Pada penelitian ini Factor contributing user acceptancenya tidak terlalu diperhatikan dan diharapkan pada penelitan selanjutnya factor contributing user acceprance harus diperhatikan dengan baik karena dengan memperhatikan factor contributing user accepiance hasilnya akan lebih baik dan model yang dihasilkan juga baik.

f. The basic structure of uses technology acceptance dari TAM terbentuk dari moderating factor yang terbagi menjadi dua variable yaitu independent variable dan dependent variable. Pada penelitian selanjutnya diharapkan dua variable tersebut diperhatikan dengan baik.

g. Dalam sistem yang bersifat mandatory, masalah sikap dan niat tidak perlu diperhatikan karena memang ciri dari sifat mandatory ini adalah dipaksakan atau diwajibkan. Dalam penelitian selanjutnya jika menggunakan model mandatory maka sikap dan niat tidak perlu diperhatikan.

h. Pada penelitian selanjutnya untuk guru dan orangtua murid dapat lebih dikelompokkan lagi dalam hal kuisionernya karena penerimaan Sofhware Education Cara Baca untuk guru dan orangtua murid itu berbeda. Kalau guru dapat membantunya dalam memberikan pembelajaran carn baca anak hanya di sekolah sedangkan untuk orangtua murid dapat membantunya pembelajaran cara baca anak hanya di rumah.

\section{DAFTAR PUSTAKA}

[1] Arief Wibowo, "Kajian Penerapan Sistem Informasi Layanan Akademik Berbasis Web Berdasarkan Pendekatan TAM: Studi Kasus di Perguruan tinggiBudi Luhur". Tesis, Perguruan tinggiBudi Luhur, Jakarta, 2006.

[2] Imam Ghozali, "Struciural Equation Model, Teori, Konsep dan Aplikasi dengan Prognam Lisrel 8.54", Penerbit Undip. Semarang, 2004.

[3] Haavelmo, T, The Prabability Approach in Econometrica. Econometrica, 1944

[4] Hair, J, F, Multivariat Data Analysis, New Jersey, Prentice Hall, 1998.

[5] Iqbaria, M. An Examination of the Factor Contributing to Micro Computer Technology Acceptance, Journal of Information System, Elsiever Ecience, USA, 1994

[6] Jogiyanto, "Analisis dan Desain Sistem Informasi" Andi Yogyakarta, 2005.

[7] Joreskog, K. G., Non-Linear Structural Equation Models : The Kenuy Judd Model eith Inieraction Effects. in G.A., Marcoulides dan R.E., Schmacker (Eds). Advanced Structural Equation Modeling.Mhwah. NJ: Erlbaum, 1973

[8] Yogesh Malhotra \& Dennis F. Galetta, "Extending The Technology Acceptance 
Model to Account for Social Influence", 1999

[9] Mc Leod, Jr, Raymond, "Sistem Informasi Manajemen" "., Jilid 1, Edisi ke 7. PT Prenhallindo, 2001

[10] Elisabet Milchrarnn, "Modelfing the Accpetance Model of Information Technology", http:/ www infonim .cz/ inforum2003 (retrieved 21 Februari 2006)

[11] Fahmi Natigor Nasution, "Teknologi Informasi Berdasarkan Apek Perilaku

[13] Nut Indriantoro, Pengaruh Compuler Anxiery Terhadap Keahlian Dosen Dalam Penggunaan Komputer, Jurnal Akmtansi dan Auditing (JAAI) Vol,3 No.1, FE UII, Yogyakarta, 2000.

[14] James A. O'brien, "Introduction to Information Svsiem". Eleventh Edition, Mc Graw Hill, 2003

[15] Syam Fazli, Dampak Kompleksiás Teknologi Informasi bagi Strategi Dan Kelangsungan Usaha, Jumal Akuntansi dan Auditing (JAAI) Vol.3 No.1, FE UII, Yogyakarta, 1999
(Behavior Ascpect)", USU Digital Library, 2004, hitp:dabrary usu ac id (retieved 16 Januari 2006)

[12] Nurlia, "Kajian Penggunaan Software AMOS/LISREL. Berdasarkan Pendekatan TAM Studi Kasus : Penggunaan Software Pada Pemodelan Persamaan Struktural di Perguruan Tinggi", Tesis, Perguruan tinggiBudi Luhur, Jakarta, 2006.

[16] AMOS 5:0, hut :/smallwaters.com. 2006

Trisnawat, Rina, Pertimbangan Perilaku dan Faktor Penentu Keberhasilan Pengembangan Sistem Informasi, Jumal Kajian Bisnis, Yogyakarta, 1998

[17] Widodo, Prabowo, P., Staisuka : Analisis Mulivariat. Seni Metode Kuantitatif. Perguruan tinggiBudi Luhur, Jakarta. 
